\title{
INTERACTION OF PHOTOCHEMICAL AND RADIATIVE \\ PROCESSES IN THE STRATOSPHERE: AN APPLICATION \\ ON THE RETRIEVAL OF CONCENTRATION PROFILES \\ FROM SATELLITE MEASUREMENTS
}

\author{
CONSTANTINOS I. CARTALIS* \\ Department of Atmospheric, Oceanic and Space Sciences, Space Physics Research Laboratory, The \\ University of Michigan, Ann Arbor, Michigan, U.S.A.
}

(Received 31 August, 1990)

\begin{abstract}
A new method is developed to determine the concentration profiles of chemical species from satellite measurements. The method takes into account the interaction of photochemical and radiative processes in the stratosphere and is applied for chemical species (nitric oxide and nitrogen dioxide) experiencing large diurnal changes. It is found that if the interaction of the photochemical and radiative processes is neglected, that is if the temporal and spatial variations of $\mathrm{NO}$ and $\mathrm{NO}_{2}$ are not considered in the radiative transfer calculations, the resulting errors for the concentration profiles for altitudes less than $20 \mathrm{~km}$ reach 100 and $5 \%$ respectively, for both sunset and sunrise. A photochemical scheme is developed capable of providing the mixing ratio profiles of $\mathrm{NO}$ and $\mathrm{NO}_{2}$ for different latitudes, altitudes and seasons and a retrieval code combining an iterative inversion algorithm, working from top of the atmosphere downwards, and a parameterization of the variability of $\mathrm{NO}$ and $\mathrm{NO}_{2}$ is also constructed. The method is used to examine the accuracy of the retrieval of the vertical concentration profiles and the new results show that the recovered profiles are in good agreement (error $5-15 \%$ ) with measured profiles (WMO, 1985) and reffect the trends of $\mathrm{NO}$ and $\mathrm{NO}_{2}$ at sunset and surrise.
\end{abstract}

\section{Description of the Problem}

In most retrieval algorithms, the chemical composition of the species under investigation is assumed to remain constant with time during the measurements. Such an approach is justified for ozone and water vapor but fails for the case of NO and $\mathrm{NO}_{2}$. The large spatial and temporal variations of $\mathrm{NO}$ and $\mathrm{NO}_{2}$ around sunrise and sunset, need to be taken into account in any attempt to invert their measured transmittances to obtain the concentration profiles.

Consider Figure 1, which describes the way the atmosphere is modeled for the treatment of the problem. If the spatial and temporal variations of $\mathrm{NO}$ and $\mathrm{NO}_{2}$ are neglected, i.e., if the $\mathrm{NO}$ and $\mathrm{NO}_{2}$ concentrations are assumed to remain constant at locations $1,2,3$, there will be an underestimation (overestimation) of NO $\left(\mathrm{NO}_{2}\right)$ at sunset and sunrise. Depending on the altitude, the errors for NO range from about $5 \%$ for altitudes between 42 and $30 \mathrm{~km}$ to $100 \%$ for altitudes

* Present affiliation: Laboratory of Meteorology, Department of Applied Physics, University of Athens, Greece. 


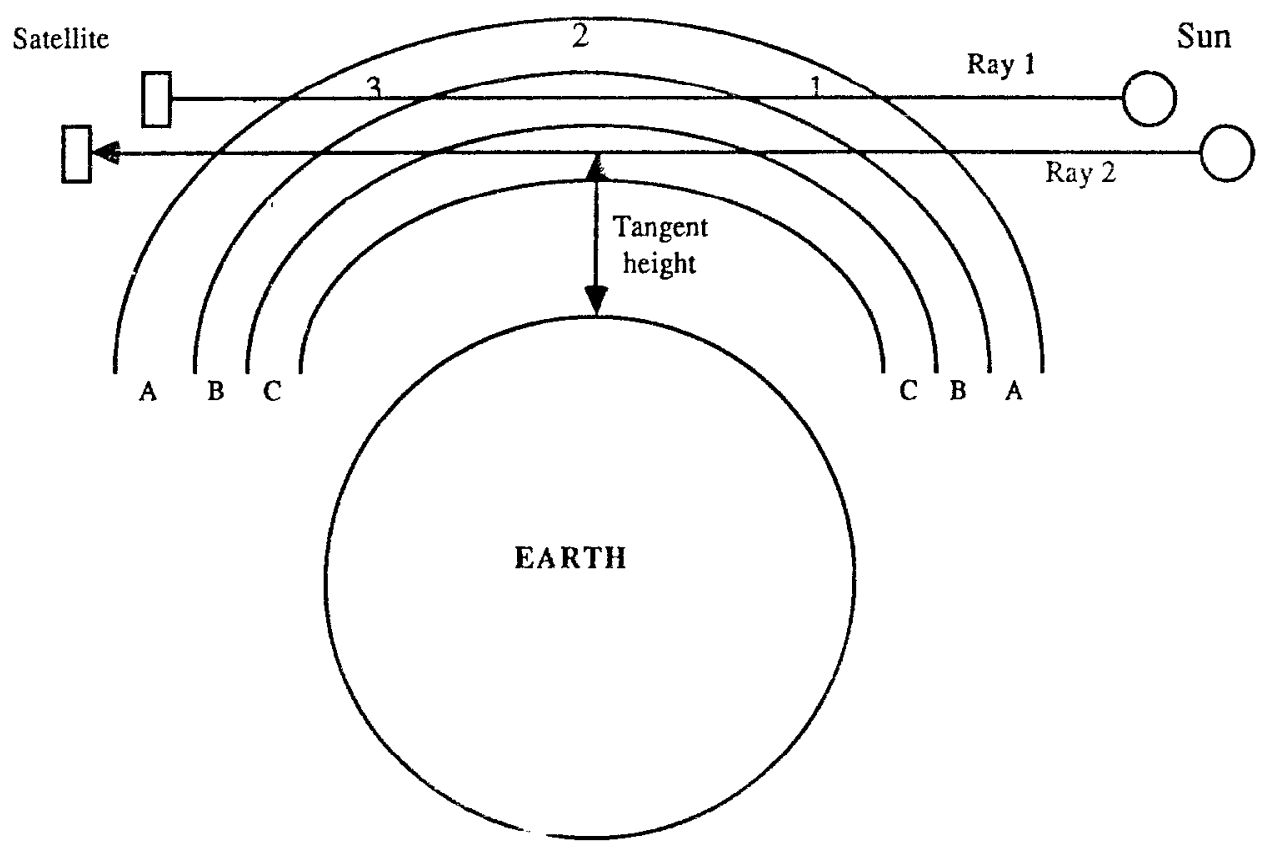

Fig. 1. Geometry illustrating the model of the atmosphere.

less than $18 \mathrm{~km}$. For $\mathrm{NO}_{2}$ the errors are significantly lower, reaching a maximum of 4 to $5 \%$ at the lower altitudes (Cartalis and Drayson, 1988).

\section{The Photochemistry of Sunset and Sunrise}

Nitric oxide and nitrogen dioxide experience rapid, large concentration changes at sunrise and sunset. Their rapid interconversion depends mostly on sunlight and ozone. Since the lifetimes of $\mathrm{NO}$ and $\mathrm{NO}_{2}$ are of the order of few minutes at sunrise and sunset, the interpretation of solar occultation measurements needs to incorporate the temporal and spatial variations of $\mathrm{NO}$ and $\mathrm{NO}_{2}$.

The oxides of nitrogen included in this study are $\mathrm{NO}, \mathrm{NO}_{2}, \mathrm{HNO}_{3}, \mathrm{~N}_{2} \mathrm{O}_{5}$ and $\mathrm{NO}_{3}$, but the major concern is focused on $\mathrm{NO}$ and $\mathrm{NO}_{2}$. The $\mathrm{NO}_{x}, \mathrm{HO}_{x}$ and $\mathrm{ClO}_{x}$ families will play important roles in a complete photochemical scheme. Difficulties arise due to the strong coupling between various reactive species because coupling will result in the inability to separate the roles of individual species. Family analysis allows us to gain insight into the important processes and interactions that affect stratospheric photochemistry. In addition families may overlap, allowing a number of chemical species to participate in two families.

A photochemical model is developed capable of simulating the concentration variations of $\mathrm{NO}$ and $\mathrm{NO}_{2}$ at sunset and sunrise. A more fully detailed description of the photochemical model can be found in Cartalis (1989). 


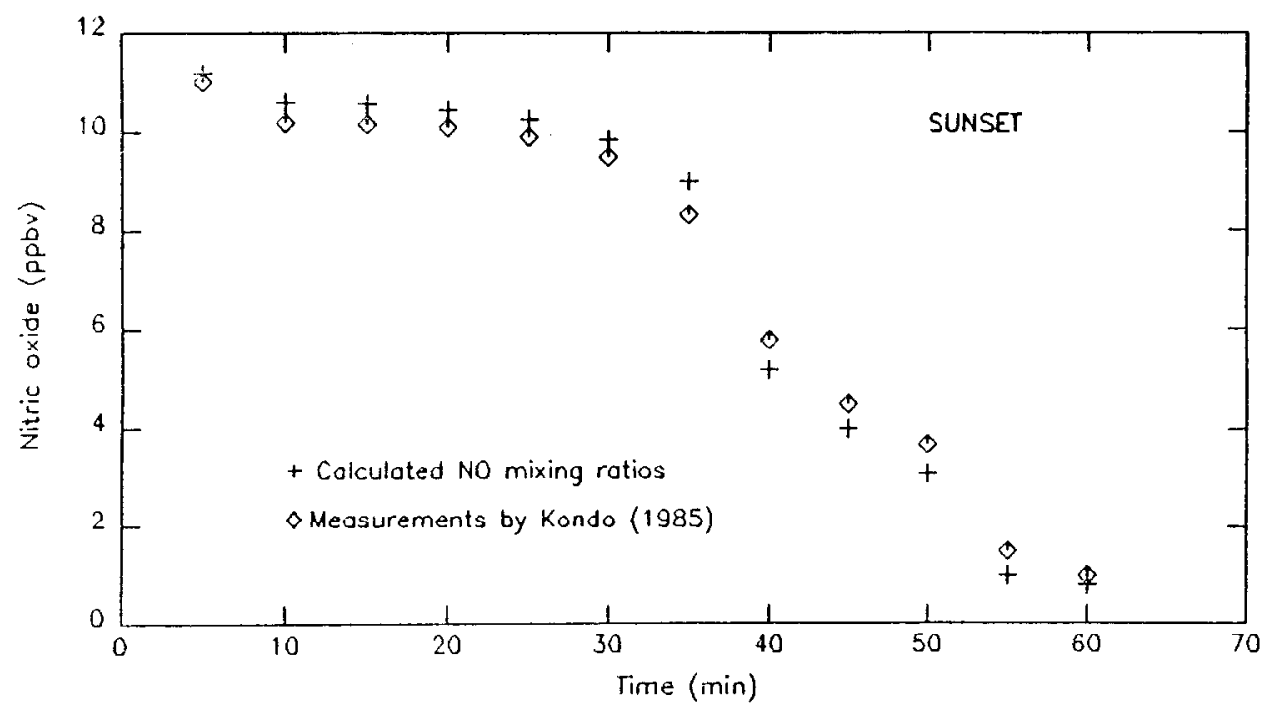

Fig. 2. Results of the photochemical scheme and observations by Kondo et al. for $\mathrm{NO}\left(\varphi=45^{\circ} \mathrm{N}\right.$, $\mathrm{z}=32 \mathrm{~km}$, Fall).

\section{Results of the Photochemical Scheme}

The computer code for solving coupled differential equations (Whitten and Hogo, 1979) is used to solve the large set of nonlinear differential equations derived from the developed photochemical scheme. The code uses a divided-difference formulation of Gear's method with time steps of $5 \mathrm{~min}$. The set of equations is difficult to solve because of its mathematical stiffness (a mathematical system is stiff if it contains eigenstates with greatly different time constants), especially at times close to sunset and sunrise where the photodissociation rates change rapidly.

The recent temperature and temperature and pressure dependent rate constants are used for the second order and third body reactions respectively (DeMore et $a l ., 1987)$. The solution of the set of non-linear differential equations will depend on the temperature and pressure profiles of the atmosphere, the rate constants of the non-photochemical reactions, the photodissociation rates and the initial values of the chemical species which take part in the photochemical scheme.

The photochemical scheme was tested for different almospheric conditions and various geographic locations. To test its validity the NO results obtained for latitude of $45^{\circ} \mathrm{N}$, altitude of $32 \mathrm{~km}$ and atmospheric conditions (temperature and pressure) for the month of September are compared to the observations by Kondo et al., (1988). Figure 2 shows the results of the photochemical scheme used in this study and the measurements by Kondo. The time scale of the abscissas is referred to the time - in minutes - during the last hour before sunset. If we take into account the number of assumptions employed for the calculation of photodissociation rates, and the uncertainty of the albedo value of Kondo's measurements, the $10-15 \%$ discrepancies in the NO mixing ratios are satisfactory. 


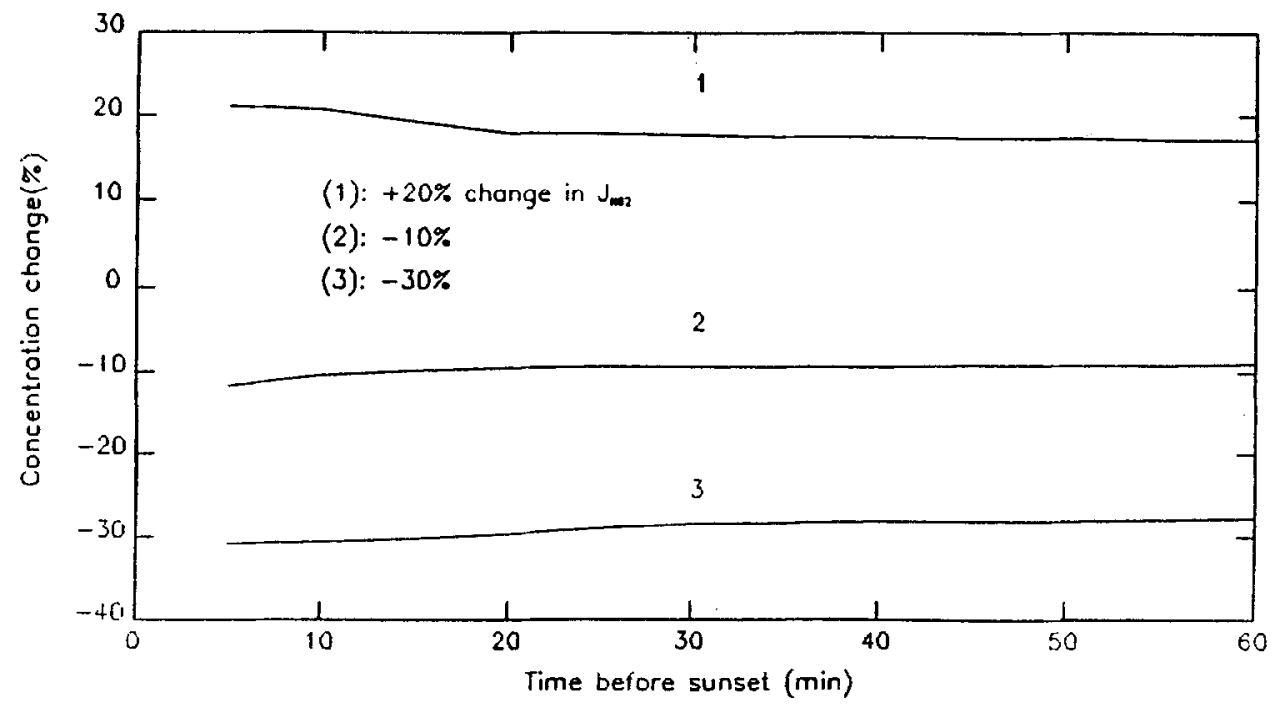

Fig. 3. Percentage changes of the $\mathrm{NO}$ mixing ratio if the photodissociation rates of $\mathrm{NO}_{2}$ are changed by $-10 \%,-30 \%$ and $+20 \%$.

\section{The Parameterization of the Photochemistry of $\mathrm{NO}$ and $\mathrm{NO}_{2}$}

The fundamental reaction which controls the photochemical cycles of $\mathrm{NO}$ and $\mathrm{NO}_{2}$ at sunset and sunrise, is the photodissociation of $\mathrm{NO}_{2}$ due to sunlight.

Figure 3 shows the percentage changes of the NO mixing ratio if the photodissociation rates of $\mathrm{NO}_{2}$ are changed by $-10 \%,-30 \%$ and $+20 \%$. In other words the photochemical scheme is run for the correct set of photodissociation rates of $\mathrm{NO}_{2}$ corresponding to a particular location, altitude and season and the resulting NO mixing ratios are compared to those resulting from the same photochemical scheme and for the same state of the atmosphere but for perturbed photodissociation rates of $\mathrm{NO}_{2}$. It is seen from Figure 3 that changes of $-10,-30$ and $20 \%$ in the photodissociation rates of $\mathrm{NO}_{2}$ result in percentage changes in the mixing ratio of nitric oxide of about the same order. This correlation is expressed mathematically as a function of latitude, season, altitude, temperature and pressure profile and time of the day (sunset or sunrise).

Figure 4 shows the results of the photochemical scheme for sunset, for the month of January, for latitude of $15^{\circ} \mathrm{N}$ and for altitude of $32 \mathrm{~km}$. The results correspond to the time interval starting one hour before sunset and it is seen that at the beginning of the hour (larger photodissociation rates correspond to the beginning of the hour), the NO changes are very small but start increasing later. The data points are fitted with a second order polynomial

$$
Y=0.3043+17.98 * X-11.985 * X^{2}
$$

where $Y$ is the NO mixing ratio and $X$ is the photodissociation rate of $\mathrm{NO}_{2}$. This calculation approach is followed for both sunrise and sunset and resulted in four 


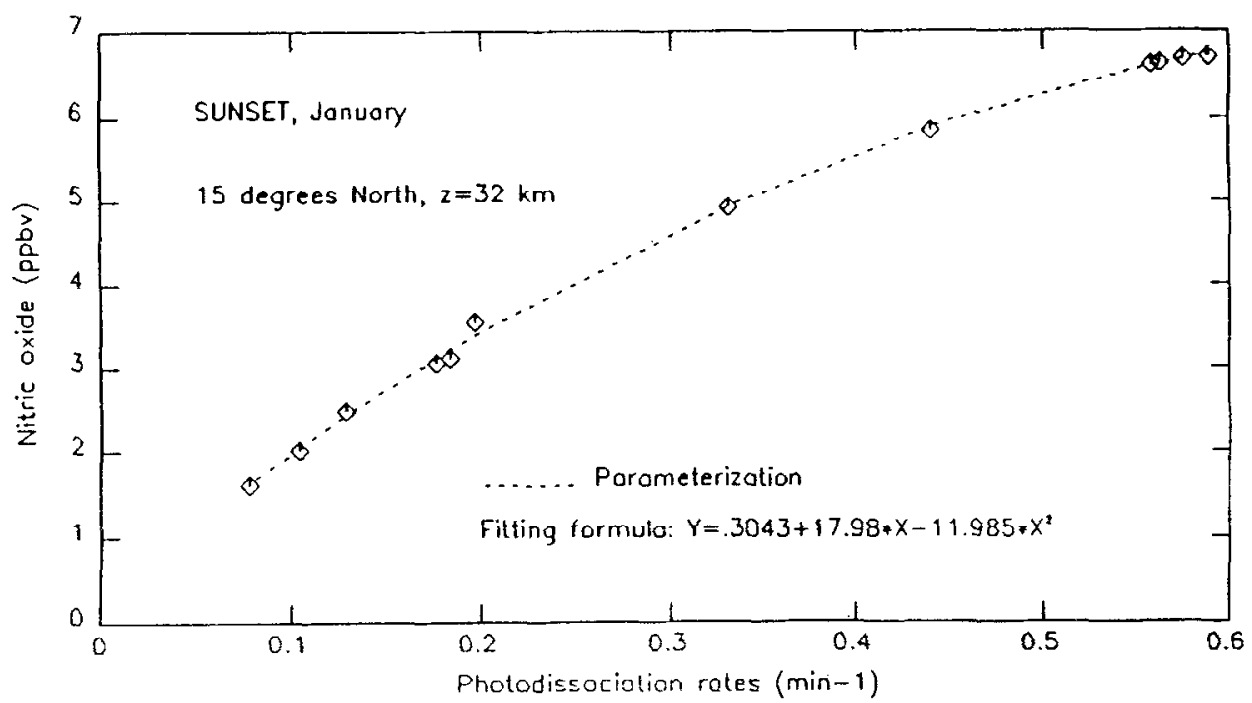

Fig. 4. Curve-fitting for sclceted case and for the hour of sunset (larger photodissociation rates correspond to the beginning of the hour before sunset). In the fitting formula $Y$ is the $\mathrm{NO}$ mixing ratio and $X$ is the $\mathrm{NO}_{2}$ photodissociation rate.

sets of formulas ( $\mathrm{NO}$ sunset, $\mathrm{NO}$ sunrise, $\mathrm{NO}_{2}$ sunset, $\mathrm{NO}_{2}$ sunrise). The sets of formulas simulate the mixing ratio profiles of $\mathrm{NO}$ and $\mathrm{NO}_{2}$ using as input such parameters as the tangent altitude, the latitude, the period of the day (sunset and sunrise) and the value of the photodissociation rate. The seasonal variability of $\mathrm{NO}$ and $\mathrm{NO}_{2}$ is taken into account through the seasonal dependence of the photodissociation rates of $\mathrm{NO}_{2}$ on season and the variability of the initial values used to initiate the photochemical scheme.

For $\mathrm{NO}$ and $\mathrm{NO}_{2}$ the general formulas for sunset and sunrise are:

For NO:

$$
\begin{array}{ll}
\mathrm{N}=\mathrm{A}+\mathrm{B} * \mathrm{PH}+\mathrm{C} * \mathrm{PH} & 12<z \leqslant 28 \mathrm{~km} \\
\mathrm{~B} & 28<z \leqslant 14 \mathrm{~km}
\end{array}
$$

For $\mathrm{NO}_{2}$ :

$$
2
$$

$$
\begin{array}{ll}
\mathrm{N}=\mathrm{A} \dashv \mathrm{B} * \mathrm{PH}+\mathrm{C} * \mathrm{PH} & 42 \leqslant z \leqslant 24 \mathrm{~km} \\
\mathrm{~B} * \mathrm{PH} & 24<z \leqslant 10 \mathrm{~km}
\end{array}
$$

where $\mathrm{N}$ is the mixing ratio of $\mathrm{NO}$ or $\mathrm{NO}_{2}$ in ppbv, $\mathrm{PH}$ the photodissociation rates of $\mathrm{NO}_{2}$ in $\mathrm{min}^{-1}$, and $\mathrm{A}, \mathrm{B}, \mathrm{C}$ coefficients which vary with tangent altitude, latitude and period of day (sunset or sunrise).

Due to the extremely low mixing ratios of NO at altitudes of 12 and $10 \mathrm{~km}$, the 
parameterization scheme does not reproduce the mixing ratios of $\mathrm{NO}$ at these altitudes.

The formulas and coefficients are based in part on scattering computations for specified model cloudless atmospheres. Therefore they are also functions of water droplets, zenith angle, surface albedo, dust particles and the ozone distribution. These parameterization formulas allow the concentration of $\mathrm{NO}$ and $\mathrm{NO}_{2}$ to be treated as variables, permitting the retrieval model to incorporate changes in the $\mathrm{NO}$ and $\mathrm{NO}_{2}$ stratospheric composition at sunset and sunrise.

\section{The Inversion Algorithm}

The main objective of the inverse algorithms of this research work is to retrieve the vertical composition structure of nitric oxide and nitrogen dioxide in the stratosphere.

It is useful to separate the retrieval model conceptually into two parts:

- the treatment of the photochemistry of $\mathrm{NO}$ and $\mathrm{NO}_{2}$ at sunset and sunrise by updating their concentration profiles;

- the iterative inversion algorithm.

The first part of the model is treated via the parameterization formulas which are described in the previous section. The second part of the model consists of the calculation of the transmission functions and the iterative process. Although lineby-line calculations provide the most accurate transmittance values, we chose to use the New Random model (or Malkmus model) for the following reasons:

- the main purpose of this study is to devise and demonstrate a scheme for incorporating the photochemistry of $\mathrm{NO}$ and $\mathrm{NO}_{2}$ at sunset and sunrise into an inversion algorithm, rather than the optimization of the inversion itself;

- the absolute accuracy of the transmittance values of $\mathrm{NO}$ and $\mathrm{NO}_{2}$ and the modulation function of $\mathrm{NO}$ is not important in this study. The model can be modified to calculate the transmittances and the NO modulation using methods based on line-by-line calculations for the inversion of the satellite data when it becomes available;

- if relatively wide spectral channels are used for the investigation of NO and $\mathrm{NO}_{2}$, line-by-line calculations require large amounts of computational time;

- Malkmus model (1967) avoids the underestimation of weak lines.

Calculations are performed in the new spectral regions defined from $1883 \mathrm{~cm}^{-1}$ to $1917 \mathrm{~cm}^{-1}$ for $\mathrm{NO}$ and from $1591 \mathrm{~cm}^{-1}$ to $1607 \mathrm{~cm}^{-1}$ for $\mathrm{NO}_{2}$. Within these spectral regions, interference is caused by methane, nitrous oxide, water vapor, carbon dioxide, ozone and aerosol particles for $\mathrm{NO}$, and by methane, nitrous oxide, water vapor and aerosols for $\mathrm{NO}_{2}$. In this study the mixing ratios of the interfering gases 
are from WMO (1985) and are assumed to be invariant with latitude, except for ozone. Calculations show that this approximation will introduce an error around $3 \%$ (mean value) for the calculated $\mathrm{NO}$ and $\mathrm{NO}_{2}$ mixing ratios at sunset and sunrise. Temperature and pressure profiles are from the 1978 Air Force Standard Atmospheres and vary with latitude and season. Two $\mathrm{km}$ vertical resolution is assumed and the transmission values are calculated for $\mathrm{NO}$ and $\mathrm{NO}_{2}$ and the interfering gases for the langent paths. Retrievals can work downwards or upwards. The latter is better in controlling the effects of random noise at high altitudes. However, in this research study the retrieval starts from the highest altitude and works downwards for the following reasons:

- uncertainties in the $\mathrm{NO}$ and $\mathrm{NO}_{2}$ mixing ratios at higher altitudes are smaller than at lower altitudes, mainly because of more accurate photodissociation rates and the slower variation of the concentration profiles.

- if the retrieval is from the bottom to the top and if the atmosphere is cloudy, instead of being cloudless as is generally assumed, any error arising from the presence of clouds will propagate upwards.

- effects for NO due to spatial/temporal variations along the ray path at sunset or sunrise are smaller at high altitudes than at low altitudes;

- in limb geometry most of the information is generally obtained at the tangent point because the absorber concentration is larger than in the layers above. However this is not the case for NO at sunset and sunrise because its mixing ratio increases rapidly with altitude.

The outline of a retrieval for $\mathrm{NO}$ or $\mathrm{NO}_{2}$ follows:

- choose month and latitude;

- assign the temperature and pressure profiles for the particular latitude and month. Assign the set of $\mathrm{NO}_{2}$ photodissociation rates and define whether the inversion is for sunrise or sunset;

- construct the mixing ratio profiles of $\mathrm{NO}$ or $\mathrm{NO}_{2}$ for sumset or sumise (hereafter assumed profiles) by using the photodissociation rates of $\mathrm{NO}_{2}$, the temperature profile and the appropriate parameterization formula;

- calculate the transmission values using the Malkmus model for the tangent paths for $\mathrm{NO}$ or $\mathrm{NO}_{2}$ and for the interfering gases;

- store the transmittances, define an initial guess mixing ratio for the top most layer and start the inversion for the concentration profiles of $\mathrm{NO}$ and $\mathrm{NO}_{2}$;

- perform a number of iterations on transmittance until an a priori set convergence criterion (i.e., accepted maximum difference between the assumed and the retrieved profile) is satisfied; 
- proceed to the next layer, using the mixing ratio in the previous layer as an initial guess;

\section{Inversion Results}

To test the accuracy of the inversion algorithm, the transmittances of nitric oxide and nitrogen dioxide and of the interfering gases are calculated for a variety of locations and seasons. Runs for selected cases are presented:

1. Nitric Oxide
a. July, $45^{\circ} \mathrm{N}$, sunset
b. January, $30^{\circ} \mathrm{N}$, sunset
c. January, equator, sunrise

\section{Nitrogen dioxide}
a. November, $60^{\circ} \mathrm{N}$, sunset
b. January, $45^{\circ} \mathrm{N}$, sunrise

The synthetic data for the transmittances are used to carry out the retrievals and to obtain the $\mathrm{NO}$ and $\mathrm{NO}_{2}$ mixing ratios. The initial guess value at the highest levels for runs $1 \mathrm{~b}$ and $2 \mathrm{a}$ is $7 \times 10^{9} \mathrm{molec} / \mathrm{cm}^{3}$, used to show convergence with poor initial value. For the remaining runs a better initial concentration of $7 \times 10^{8} \mathrm{molec} / \mathrm{cm}^{3}$ is chosen to speed the inversion procedures. The retrieved NO mixing ratio profile for $1 \mathrm{a}$ is shown in Figure $5(\mathrm{a}, \mathrm{b})$ and in Figure $6(\mathrm{a}, \mathrm{b})$ for run $1 b$.

The importance of a good initial guess profile can be seen comparing Figures $5(\mathrm{a})$, and 6(a). Retrieval $1 \mathrm{~b}$ is characterized by a $5 \%$ error at the topmost layer. Such an error will affect the retrievals at the lower altitudes until approximately tangent altitude of $34 \mathrm{~km}$ where the increased NO number density smoothes out the error. Retrieval 1a starts with a good initial profile and gives a more accurate retrieved profile. Finally Figure $7(\mathrm{a}, \mathrm{b})$ shows the NO profiles for run $1 \mathrm{c}$, and Figures $8(\mathrm{a}, \mathrm{b})$ and $9(\mathrm{a}, \mathrm{b})$ show the retrieved $\mathrm{NO}_{2}$ profiles for runs $2 \mathrm{a}$ and $2 \mathrm{~b}$, respectively.

Overall, $\mathrm{NO}_{2}$ retrievals are more accurate than $\mathrm{NO}$ retrievals, the difference in accuracy being more pronounced at lower altitudes due to the smaller temporal and spatial variability of $\mathrm{NO}_{2}$ compared to the variations of $\mathrm{NO}$.

\section{Conclusions}

The inversion code provides results which satisfy accuracy expectations (within 5$15 \%$ ), for both nitric oxide and nitrogen dioxide at sunset and sunrise over a wide range of geographic locations and seasons. Accuracies are for single profile retrievals and errors will be reduced for zonally averaged profiles or total column amounts. The algorithm's major advantage is that it effectively takes into account the interaction of photochemical and radiative processes. Therefore, by including the sunsct and sunrise photochemistry of $\mathrm{NO}$ and $\mathrm{NO}_{2}$ in the inversion procedures, 

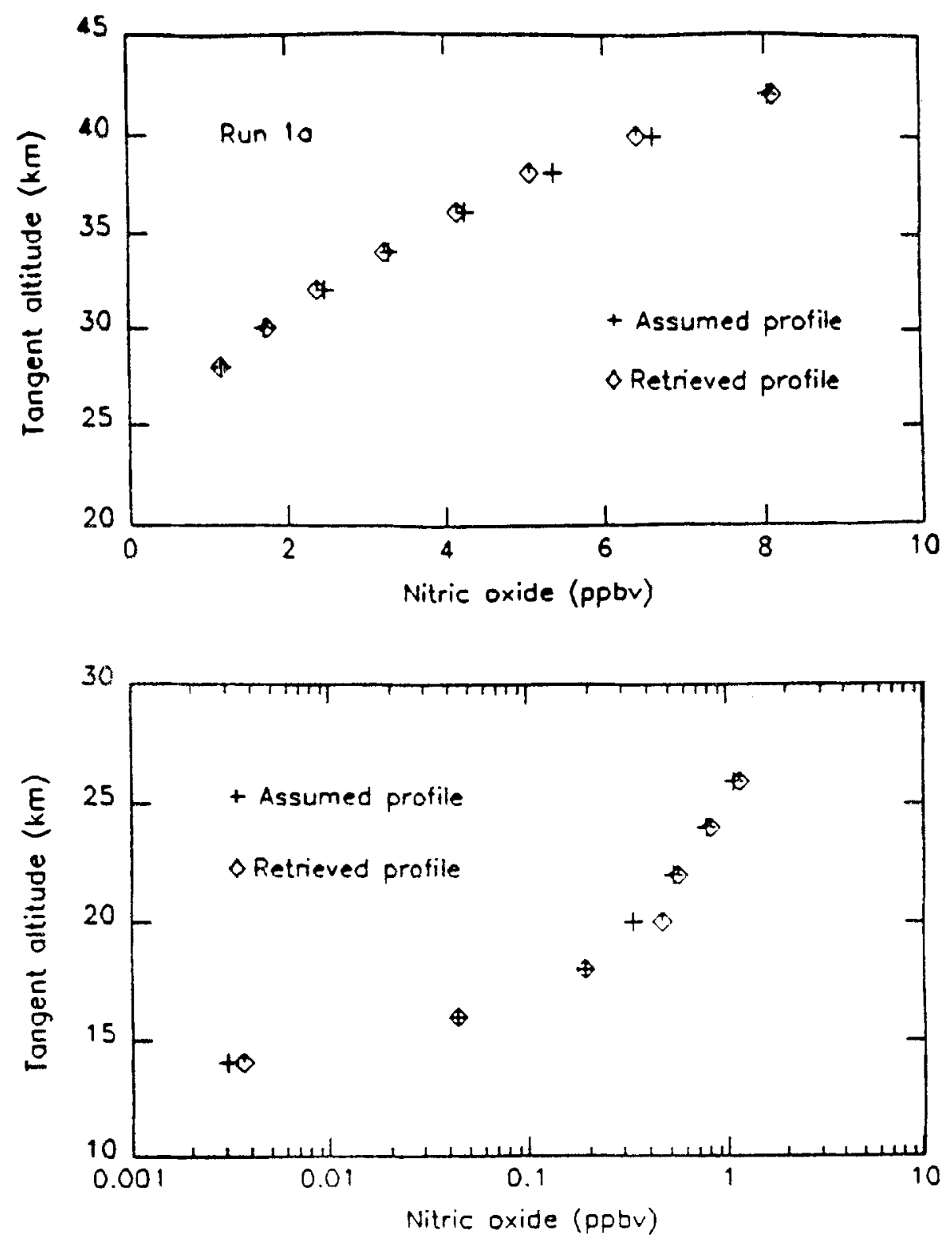

Fig. 5. NO retrieval at sunset (July, $45^{\circ} \mathrm{N}$ ). (a) Higher range of altitudes. (b) Lower range of altitudes.

it eliminates the large errors which result if the temporal and spatial variations of the $\mathrm{NO}$ and $\mathrm{NO}_{2}$ are neglected.

$\mathrm{NO}_{2}$ retrievals are in general more accurate than NO retrievals for both sunset and sunrise. This can be attributed to the smaller temporal and spatial variability of nitrogen dioxide at sunset/sunrise and to the larger number density distribution of $\mathrm{NO}_{2}$ at most altitudes.

$\mathrm{NO}_{2}$ retrievals are more sensitive to errors and poor choice of an initial guess 

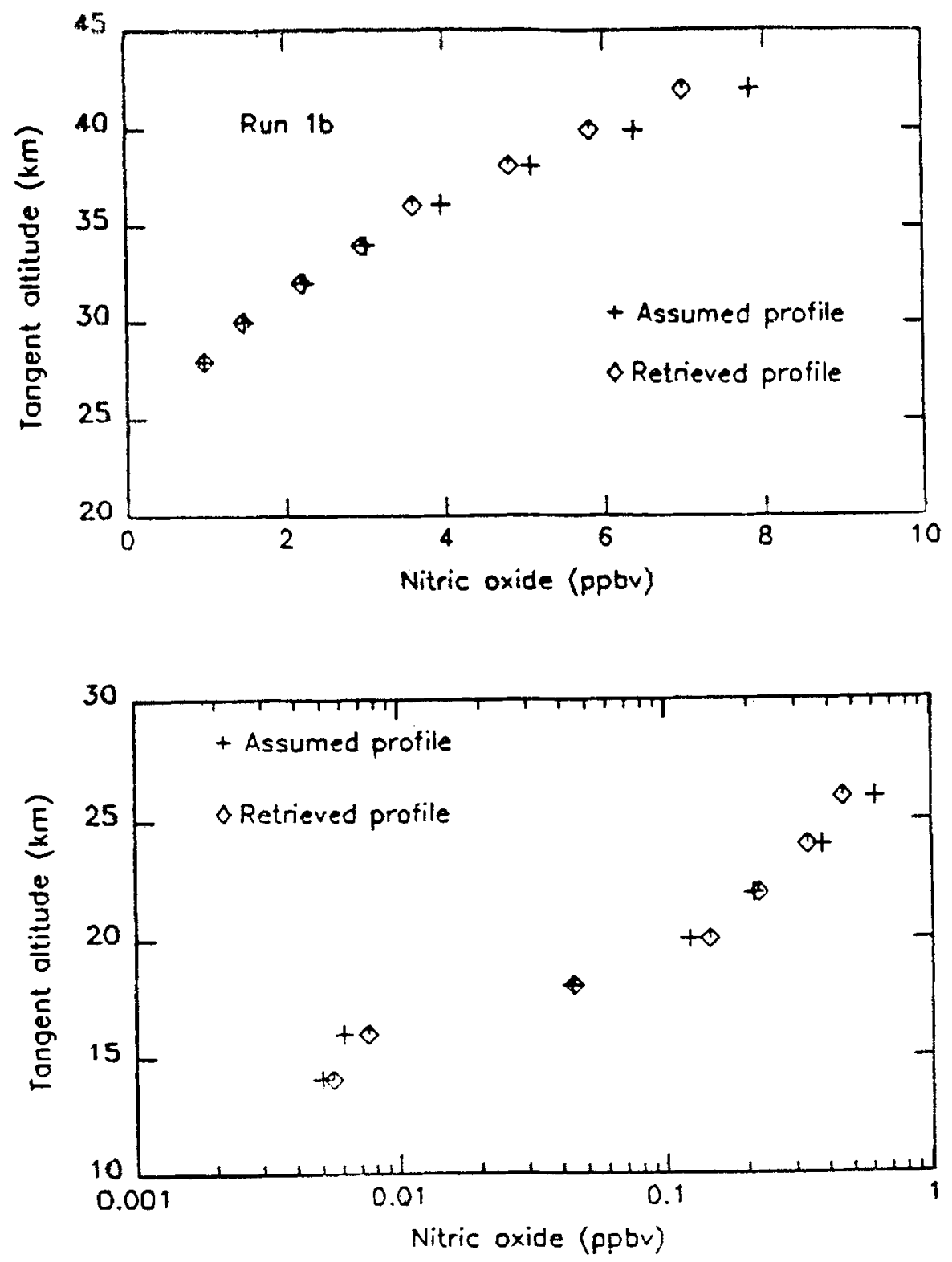

Fig. 6. NO retrieval at sunset (January, $\left.30^{\circ} \mathrm{N}\right)$.

profile at the topmost layers ( 42 to $40 \mathrm{~km}$ ). This is because $\mathrm{NO}_{2}$ has smaller number density than NO at the layers from 42 to $40 \mathrm{~km}$, and becausc at high altitudes $\mathrm{NO}_{2}$ changes are directly proportional to $\mathrm{NO}$ changes and therefore more difficult to parameterize.

Sunset and sunrise retrievals are of the same accuracy for a cloudless atmosphere. The retrieval model works best if the atmosphere is cloudless, but if 

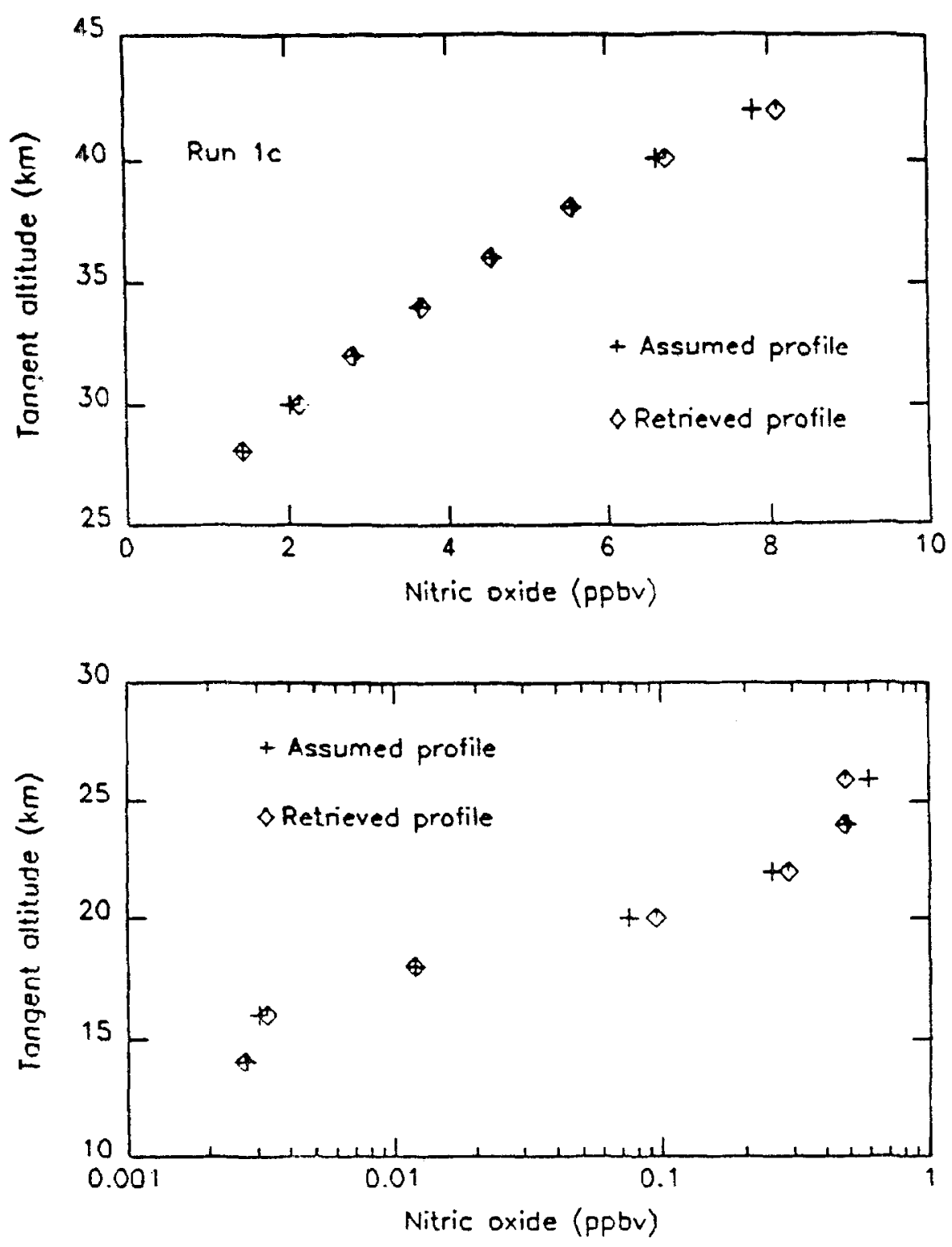

Fig. 7. NO retrieval for sunrise at the equator.

information on cloud coverage is available corrections can be applied for the mixing ratios below $20 \mathrm{~km}$.

The performance of the model is tested by an extensive error analysis and it is found that errors are more important at low altitudes. This is a direct consequence of the increased temporal and spatial variability of $\mathrm{NO}$ and $\mathrm{NO}_{2}$ at low altitudes where mixing ratios are as low as 0.003 and $0.1 \mathrm{ppbv}$ for $\mathrm{NO}$ and $\mathrm{NO}_{2}$ respectively. 

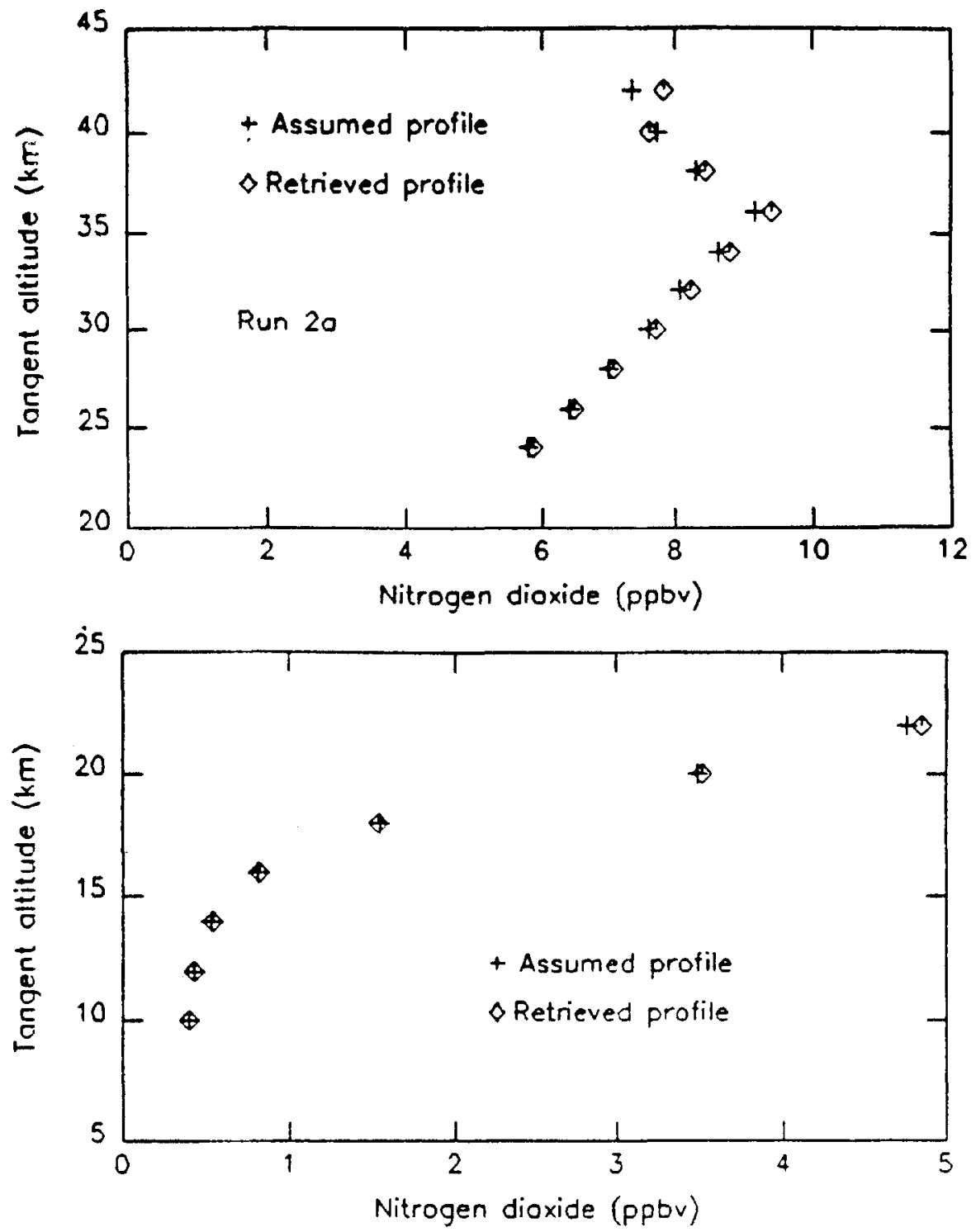

Fig. 8. $\mathrm{NO}_{2}$ retrieval at sunset (November, $60^{\circ} \mathrm{N}$ ).

The method is stable in the presence of most systematic and random errors but is sensitive to noise at low altitudes.

\section{Acknowledgements}

The author wishes to acknowledge with much appreciation the assistance and invaluable advice of Dr. S. R. Drayson in the development of this research work. 

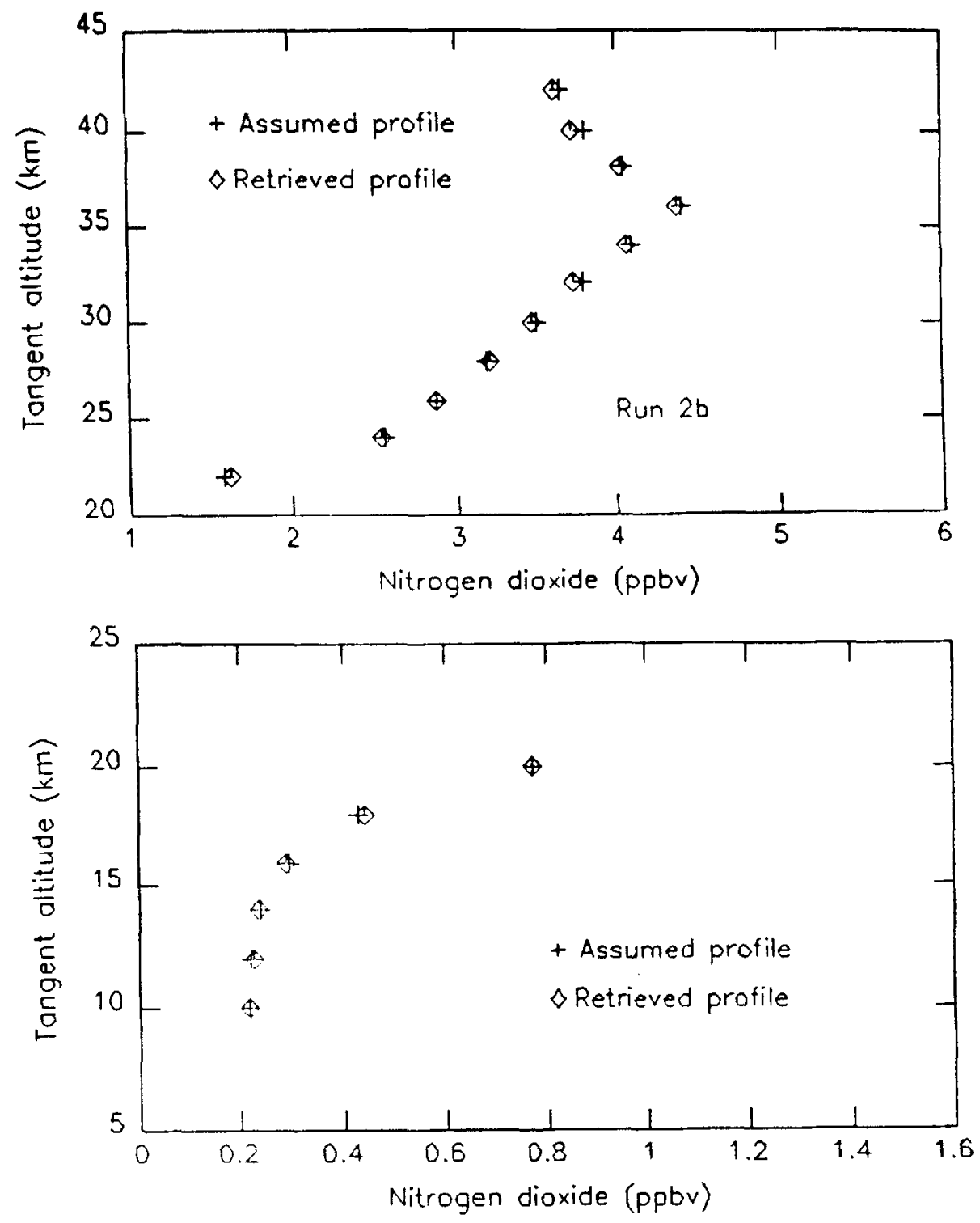

Fig. 9. $\mathrm{NO}_{2}$ retrieval at sunrise (January, $45^{\circ} \mathrm{N}$ ).

I would also like to thank Drs. W. Kuhn and J. Barker for their helpful suggestions. This material is based upon work supported by the NASA Langley Research Center. Part of this paper was presented at the Symposium of Remote Sensing of Atmospheric Constituents, IAMAP 89.

\section{References}


Satellite Solar Occultation Measurements at Sunset and Sunrise', Ph.D. dissertation, University of Michigan, 220 pp., available from University Microfilms International, Ann Arbor, MI.

Cartalis, C. I. and Drayson, S. R.: 1988, 'The Retrieval of Nitric Oxide and Nitrogen Dioxide from Solar Occultation Measurements', Proceedings of the International Radiation Symposium, Lille, pp. 511-515, Deepak.

Cartalis, C. I. and Drayson, S. R.: 1989, 'Parameterization of the Photochemistry of Nitric Oxide and Nitrogen Dioxide at Sunset and Sunrise and its Applicability in Inversion Codes', Paper presented at the Symposium of Remote Sensing of Atmospheric Constituents, IAMAP 89, Reading, July 31August 15.

DeMore, W. B., Molina, M. J., Sander, S. P., Golden, D. M., Hampson, R. F., Kurylo, M. J., Howard, C. J., and Ravishankara, A. R.: 1987, 'Chemical Kinetics and Photochemical Data for Use in Stratospheric Modeling', Evaluation number 6, JPL, 1983, 1985, 1987.

Kondo, Y., Matthews, W. A., Aimedieu, P., and Robbins, D. E.: 1988, 'Diurnal Variation of NO at $32 \mathrm{~km}$ : Measurements and Interpretation', J. Geophys. Res. 93, 2451-2458.

Malkmus, W.: 'Random Lorentz Band Model with Exponential Tailed $S\{-1\}$ Line Intensity Distribution Function', J. Opt. Soc. Am. 57, 323.

Standard Atmosphere Publication, U.S. Government Printing Office, Washington, D.C., 1977.

Whitten G. Z. and Hogo, H.: 1979, 'CHEMK: A Computer Modeling Scheme for Chemical Kinetics', Environmental Sciences Research Laboratory, 1979.

World Meteorological Organization, Atmospheric Ozone, 1981, 1985. 